\title{
XVII.
}

\section{Beitrag zur Kenntniss des Epithels und der Driisen des menschlichen Kehlkopfes im gesunden und im kranken Zustande.}

\author{
Von Dr. Rudolf Heymann, \\ Privatdocenten an der Universität in Leipzig.
}

(Hierzu Taf. X-XI.)

Virchow hat in dem Vortrage über Pachydermia laryngis, den er im Juli 1887 in der medicinischen Gesellschaft zu Berlin gehalten ${ }^{1}$ ), darauf hingewiesen, dass es vielleicht nützlich sein dürfte, den zuerst unter seiner Leitung von Rheiner in Würaburg im Jahre 1851/52 genauer untersuchten Verhältnissen des Kehlkopfepithels einmal wieder grössere Aufmerksamkeit zuzuwenden.

Angeregt durch diese Bemerkung, babe ich im Sommer 1888 während eines mehrmonatlichen Aufenthaltes in Wien in dem dortigen anatomischen Institut, auf der Abtheilung des Herrn Professor Dr. Toldt, eine Anzahl von menschlichen Kehlköpfen, behufs Feststellung der Anordnung der Epithelien in denselben, mikroskopisch untersucht. Im Verlaufe der Untersuchungen lenkte ich meine Aufmerksamkeit noch auf einige andere Verhältnisse, die wegen ihrer Beziehuugen zu pathologischen Prozessen im Kehlkopfe von Interesse sein dürften.

Das von mir untersuchte Material bestand, abgesehen von einigen Kehlköpfen, deren Epithel, theils in Folge ausgebreiteter Maceration, theils in Folge aufgelagerten Secretes, in seinen feineren Verhältnissen nicht mehr sicher zu erkennen war, von denen der eine aber sonst Bemerkenswerthes darbot, aus 12 Kehlköpfen. Davon gehörte No. 1 einem 40jährigen Manne an. No. 2 und 3 waren Kehlköpfe, bei denen weder über das Alter, noch über die Todesursache der Personen, denen sie im Leben

1) Deutsche medicin. Wouhenschr. 1887. S. 694. 


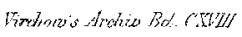
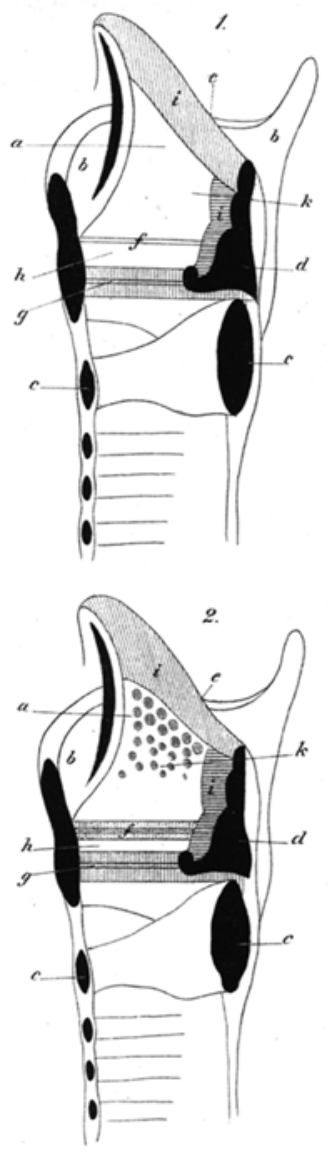

3.

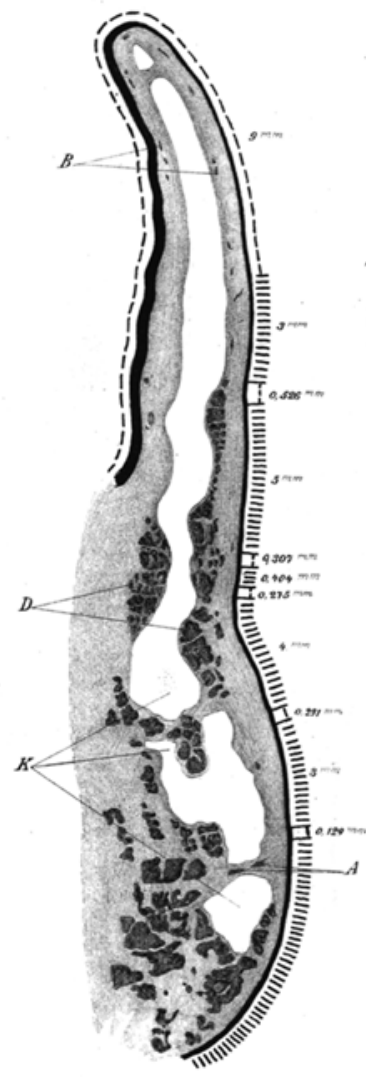

4.

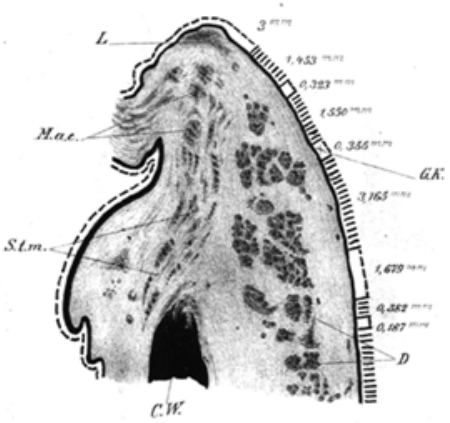

6.
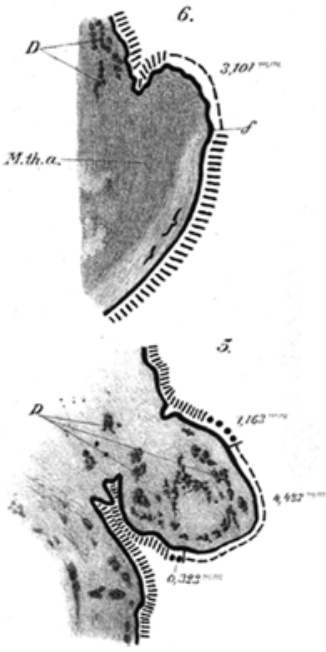

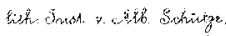


7.
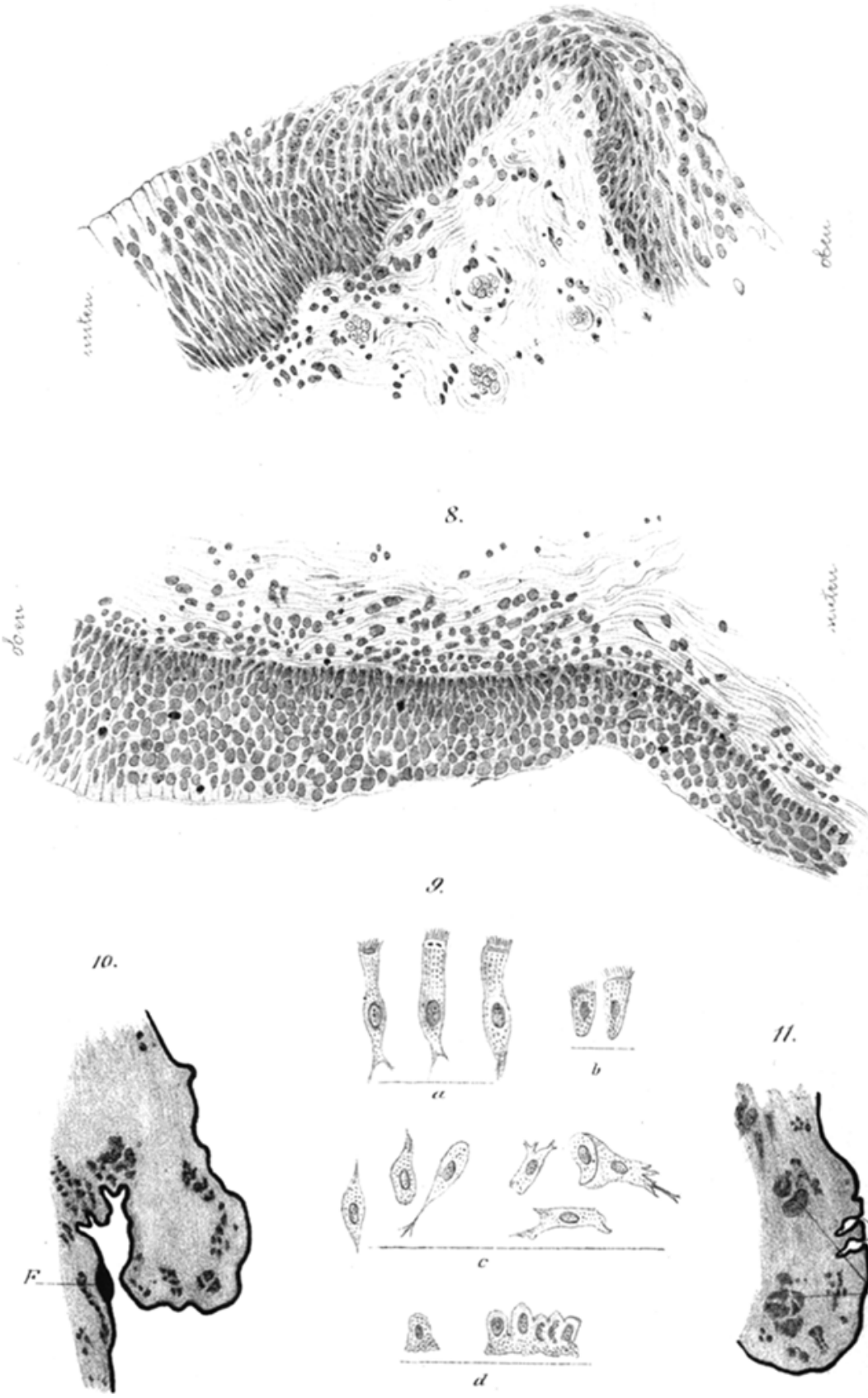

II.

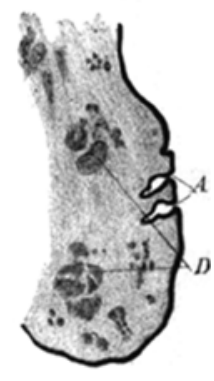

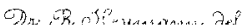

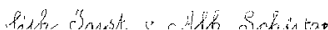


angehört hatten, etwas bekannt war. - No. 4, der Kehlkopf eines 40jährigen Potators, der im Reconvalescenzstadium einer Pneumonia crouposa mit Herzschwäche nach einer reichlichen Mahlzeit plötzlich verstorben war, zeigte makroskopisch, ausser einigen oberflächlichen Substanzverlusten, leichten Epithelabschilferungen an der hinteren Fläche des Kehldeckels und an den Taschenbändern, die bei der Herausnahme und Eröffnung des Kehlkopfes entstanden sein mochten, unregelmässig papillomatöse Verdickungen, an den Rändern der wahren Stimmbänder und unmittelbar unterhalb derselben, deren mikroskopisches Bild mit dem Befunde der Pachydermia laryngis Virchow's überein-

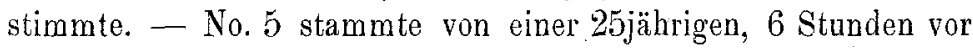
der Herausnahme des Kehlkopfes verstorbenen Puerpera. No. 6 wurde 12 Stunden post mortem aus der Leiche eines 45jährigen, an Cystitis und Pyelonephritis verstorbenen Mannes herausgenommen. - No. 7, von einer 6 Stunden zuvor an Insufficientia valvularum aorticarum verstorbenen $42 j a ̈ h r i g e n$ Frau stammend, zeigte mässige Stauungserscheinungen, besonders an der hinteren Wand. - No. 8, der Kehlkopf eiver 41jährigen Frau mit Carcinoma uteri. - No. 9, von einem todtgebornen, reifen Knaben, bot makroskopisch die Erscheinungen der Staung dar. - No. 10 stammte von einer 28jährigen, No. 11 von einer 26jährigen und No. 12 von einer 23jährigen Puerpera.

Soweit im Vorstehenden nicht ausdrücklich etwas Pathologisches angeführt worden ist, erschienen die Kehlköpfe makroskopisch in jeder Hinsicht vollkommen normal.

Die Kehlköpfe No. 1, 2, 3, 11 und 12 erhielt ich bereits in den Erhärtungsflüssigkeiten liegend. Die übrigen aber, die von Hern Dr. Zemann, 1. Assistenten am pathologischen Institut in Wien, gütiger Weise in meinem Beisein und möglichst früh aus der Leiche entfernt wurden, habe ich zunächst, um das der Schleimbaut anhaftende, die Klarheit der Bilder sehr beeinträchtigende Secret möglichst gründlich zu entfernen, kurze Zeit - etwa $\frac{1}{4}-\frac{1}{2}$ Stunde - in physiologische Kochsalzlösung gelegt und dann noch mit physiologischer Kochsalzlösung in feinem Strahle abgespült. Von den durch medianen Sagittalschnitt in 2 symmetrische Hälften zerlegten Kehlköpfen kam die eine Hälfte zur Erhärtung in Alkohol, die andere in Müller'sche 
Flüssigkeit. Nach genügender Erhärtung in Alkohol wurden die vorsichtig von dem Knorpelgerüst abpräparirten Weichtheile in Celloidin eingebettet, mit dem Mikrotom geschnitten und die Schnitte theils in Bismarckbraun, theils in der Böhmer'schen Hämatoxylin]ösung, zumeist aber in der Grenacher'schen Alauncarminlösung gefärbt. Die in Müller'scher Flüssigkeit liegenden Kehlkopftheile wurden, nachdem sie 4-8 Tage in der Flüssigkeit gelegen, zur Herstellung von Zupfpräparaten verwendet, der Rest aber dann weiter in Alkohol erhärtet und in der gleichen Weise behandelt, wie die von Anfang an in Alkohol liegenden Theile.

Gegenüber der früher herrschenden Anschauung, dass die Schleimhaut des Kehlkopfes, ebenso wie die der Trachea, in ihrer ganzen Ausdehnung Flimmerepithel trage, wurde zuerst von Carl Fr. Naumann ${ }^{1}$ ) gezeigt, dass man entlang dem Rande der wahren Stimmbänder regelmässig einen Streifen Plattenepithel findet ${ }^{2}$ ).

Kurze Zeit nach dem schwedischen Forscher machte Rheiner seine obenerwähnten Untersuchungen ${ }^{3}$ ). Das Ergebniss derselben war die Erkenntniss, dass der an dem freien Rande der wahren Stimmbänder regelmässig vorhandene Streifen von geschichtetem Plattenepithel einen Ausläufer des Schlundepithels darstellt, mit welchem er durch das sattelförmige Interstitium zwischen den beiden Giessbeckenknorpeln unmittelbar zusammenhängt und mit dem er auch seiner Structur und dem Grössenverhältnisse der ihn zusammensetzenden Zellen nach im Wesentlichen übereinstimmt. Aber nicht nur im Interstitium interarytaenoideum greift das Schlundepithel auf das Kehlkopfinnere über, sondern es überschreitet die durch den freien Rand des Kehldeckels, die ary-epiglottischen Falten und die beiden Giessbeckenknorpel gebildete obere Grenze der Kehlkopfshöhle an allen Punkten, bei

1) Carl Fr. Naumann, Om byggnaden af luftröhrschufvndet hos den fullväxta menniskan. Lund. 1851.

2) Vgl. auch Luschka, Der Kehlkopf des Menschen. Tübingen 1871. S. 170 .

3) H. Rheiner, Die Ausbreitung der Epithelien im Keblkopf. Verhandlungen der physikal.- med. Gesellschaft in Würzburg. Bd. 3. S. 222. Würzb. 1852 . 
dem einen Individuum mehr, bei dem anderen weniger weit. Die Auskleidung des Kehlkopfinnern trägt demnach zunächst dem oberen Rande Plattenepithel, beim Erwachsenen in einer durchschnittlichen Breite von 2-3 Linien, unterhalb dieses Saumes aber, mit Ausnahme des freien Randes der wahren Stimmbänder und der Regio interarytaenoidea, die von Pflasterzellen bedeckt sind, ein flimmerndes Cylinderepithel (Fig. 1).

Uebereinstimmende Angaben über die Ausbreitung der verschiedenen Epithelien im Kehlkopfe finden sich ferner bei Henle ${ }^{1}$ ), Verson ${ }^{2}$ ) und Luschka ${ }^{3}$.

Davis modificirte diese Lehre ${ }^{4}$ ), indem er nachwies, dass sich an der hinteren Fläche des Kehldeckels an den Saum von Plattenepithel, der den freien Rand desselben umgiebt, zunächst eine Zone anschliesst, in der das Flimmerepithel von zahlreichen, in ihrer Grösse and Anordnung sehr wechselnden, kleinen Inseln von Plattenepithel unterbrochen wird. Diese Inseln nehmen von oben nach unten, sowie von den Rändern gegen die Mitte zu an Grösse und Häufigkeit ab. Ausserdem befindet sich nach Davis auch am Rande des oberen Stimmbandes Plattenepithel als schmaler Streifen, der zum Theil auch noch die Innenfläche des Taschenbandes überzieht. Auch in der Nähe des freien Randes dieser Leiste liegen kleine, abgeschlossene Inseln platter Zellen in geringer Zahl in dem sonst flimmernden Epithel.

In Tebereinstimmung mit diesen Angaben früherer Untersucher habe ich nun gefunden, dass das geschichtete Plattenepithel, welches die Mundhöhle und den Pharynx auskleidet, die obere Grenze der Kehlkopfshöhle bei sämmtlichen von mir untersuchten Kehlköpfen noch ein Stück weit überschreitet. Der so gebildete Saum von Plattenepithel ist aber nicht nur bei ver-

1) Henle, Handb. der Eingeweidelehre. Braunschweig 1877. 2. Aufl. S. 273.

$\left.{ }^{2}\right)$ Verson, Beiträge zur Kenntniss des Keblkopfes und der Trachea. Sitzungsber. d. math.-naturw. Classe der k. k. Akad. d. Wissensch. zu Wien. 1868. Bd. 57. Abth. 1. S. 1093 ff. und Stricker, Handbuch der Gewebelehre. Bd.1. S. 456 ff.

3) Luschka, Die Schleimhaut des Cavum laryngis. Arch. f. mikrosk. Anat. Bd.5. 1869. S. 126 und Luschka, Der Kehlkopf des Menschen. Tübingen 1871. S. 170 .

4) Davis, Die becherförmigen Organe des Keblkopfes. Arch. f. mikrosk. Anat. Bd. 14. 1877. S. 158. 
schiedenen K hlköpfen von verschiedener Breite, sondern er bietet auch an verschiedenen Stellen desselben Kehlkopfes eine verschiedene Ausdehnung dar und zwar in der Weise, dass derselbe regelmässig vorn an der Epiglottis seine grösste Breite besitzt, dass er aber in seinem weiteren Verlaufe nach hinten $z$ an den ary-epiglottischen Falten immer schmäler und schmäler wird. An das Gebiet, welches durchaus von Plattenepithel bedeckt ist, schliesst sich nach unten überall ein Gebiet an, auf dem die beiden Arten des Epithels gleichsam um die Herrschaft streiten. Es finden sich nehmlich nicht nur auf der hinteren Fläche des Kehldeckels, wie Davis gezeigt hat, sondern auch auf der Membrana quadrangularis Tourtual's, die sich zwischen dem Seitenrande der Epiglottis und der vorderen Kante des Giessbeckenknorpels ausspannt, wach unten in das falsche Stimmband übergeht und oben von der Plica ary-epiglottica umsäumt wird ${ }^{1}$ ), - zunächst noch zahlreiche Inseln von Plattenepithel in das Cylinderepithel eingelagert. Bieten diese Inseln auch hinsichtlich ihrer Grösse, sowie hinsichtlich ihrer Anordnung einen ziemlich beträchtlichen Wechsel dar, so lässt sich im Allgemeinen die Regel aufstellen, dass dieselben weiter oben, zunächst dem zusammenhängenden Plattenepithel grösser und dichter sind, weiter nach unten zu aber relativ immer kleiner und spärlicher werden, bis schliesslich das Flimmerepithel die ausschliessliche Herrschaft erlangt.

Als Beispiele dieser Anordnung mögen die Figuren 3 und 4 dienen, welche 5 fache Vergrösserungen von Präparaten des Kehlkopfes darstellen, der in obiger Aufzählung mit No. 1 bezeichnet worden ist. Fig. 3, ein Sagittalschnitt durch die Epiglottis, zeigt, wie das Plattenepithel von der vorderen Fläche des Kehldeckels auf die hintere Fläche übergreift und hier $9 \mathrm{~mm}$ weit die Decke der Schleimhaut bildet. Dann kommt $3 \mathrm{~mm}$ weit Flimmerepithel. Hieran schliesst sich eine Insel von Plattenepithel, die einen Längsdurchmesser von $0,526 \mathrm{~mm}$ besitzt und an die sich nach unten $z a$ wieder $5 \mathrm{~mm}$ weit Flimmerepithel anschliesst. Darauf folgen zwei kleine Inseln von Plattenepithel, die durch eine nur $0,404 \mathrm{~mm}$ grosse Strecke Flimmerepithel von

1) Vgl. Merkel, Anatomie und Physiologie des menschl. Stimm- und Sprachorgans. Antbropophonik. 1863. S. 10\%. 
einander getrennt sind und von denen die obere $0,307 \mathrm{~mm}$, die untere $0,275 \mathrm{~mm}$ lang ist. $4 \mathrm{~mm}$ weit kommt nun wieder Flimmerepithel, darauf $0,291 \mathrm{~mm}$ Plattenepithel. $3 \mathrm{~mm}$ tiefer befindet sich die letzte Unterbrechung des Flimmerepithels, welche durch eine nur $0,129 \mathrm{~mm}$ grosse Insel von Plattenepithel gebildet wird.

Ganz ähnliche Verhältnisse zeigt Fig. 4, ein Frontalschnitt durch das hintere Drittel der rechten ary-epiglottischen Falte, der in seinem unteren Abschnitt die Cartilago Wrisbergii etwas schrïg getroffen hat. Das Plattenepithel überschreitet hier den Rand der Plica ary-epiglottica $3 \mathrm{~mm}$ weit, dann wird es auf einer Strecke von $1,453 \mathrm{~mm}$ von Flimmerepithel abgelöst. Darauf folgt eine $0,323 \mathrm{~mm}$ grosse Insel von Plattenepithel, dann wieder $1,550 \mathrm{~mm}$ Flimmerepithel. Die sich nun anschliessende Insel von Plattenepithel, die $0,355 \mathrm{~mm}$ lang ist, zeichnet sich dadurch aus, dass sie drei Geschmacksknospen enthält. Weiter abwärts folgt auf eine $3,165 \mathrm{~mm}$ lange Strecke Flimmerepithel eine grössere Insel von Plattenepithel, - sie hat einen Längsdurchmesser von $1,679 \mathrm{~mm}$, - dann wieder $0,582 \mathrm{~mm}$ Flimmerzellen und nochmals $0,187 \mathrm{~mm}$ Plattenepithel. Hieran schliesst sich dann nach unten eine ununterbrochene Decke von Flimmerepithel.

In der Mehrzahl der Fälle geht vun das flimmernde $\mathrm{Cy}_{y}$ linderepithel von der Membrana quadrangularis olne weitere Unterbrechung über das Taschenband hinweg auf den Sinus Morgagni über. Daneben giebt es aber auch eine, wie es scheint, nicht so gar kleine Zahl von Fällen, bei denen der Flimmerüberzug der Membrana quadrangularis von dem des Sinus Morgagni durch einen Streifen von Pflasterzellen getrennt erscheint, der sich am Rande des Taschenbandes hinzieht und auch noch ein Stück auf die mediale Fläche des Tasehenbandes übergreift. Letzteres Verhalten wird, wie oben erwähnt, von Davis (a. a. O.) als die Regel hingestellt. Unter den von mir untersuchten Kehlköpfen zeigte der Kehlkopf des 40jährigen Mannes No. 1, der mit No. 10 bezeichnete Kehlkopf einer 28jährigen Puerpera und No. 9, der Kehlkopf des todtgebornen Knaben, auf den wir später noch ausführlicher zurückliommen werden, die zuletzt beschriebene Anordnung des Epithels, die also, in so weit man nach einer so geringen Zahl von Fällen überhaupt berechtigt ist, einen Schluss 
zu ziehen, weder mit dem Alter, noch mit dem Geschlecht des Individuums irgendwie zusammenzuhängen scheint. - Fig. 5, welche dieses Verhalten darstellt, ist die 5 fache Vergrösserung eines Frontalschnittes durch das rechte Taschenband von Kehlkopf No. 1.

Der freie Rand der wahren Stimmbänder trägt, nach der übereinstimmenden Angabe sämmtlicher Untersucher, einen schmalen Streifen Plattenepithel. Die Breite dieses Streifens ist wechselnd; sie schwankte in meinen Fällen zwischen $3 \mathrm{~mm}$ und $1 \mathrm{~cm}$, betrug aber zumeist nur etwa $3-4 \mathrm{~mm}$. Abgesehen von den Fällen mit extrem grosser Ausbreitung des Plattenepithels, habe ich die untere Grenze desselben meist auf der Höhe eines kleinen Fältchens der Schleimhaut gefunden, welches, hinten in der Regel am stärksten ausgebildet, unterhalb des freien Randes des Stimmbandes und parallel demselben verläuft und constant vorhanden ist ${ }^{1}$ ). Unterhalb des eben geschilderten Streifens findet sich überall flimmerndes Cylinderepithel (Fig. 6), das jedoch, ebenso wie es Brasch für das Flimmerepithel der Trachea nachgewiesen hat, hier und da kleine Inseln von Plattenepithel einschliesst.

Sowohl der Streifen Plattenepithel am Rande des Stimmbandes, wie auch der nur mitunter vorhandene Streifen am Taschenbande hängt nach hinten mit dem Streifen von Plattenepithel zusammen, der sich vom Schlunde her durch das Interstitium interarytaenoideum in den Kehlkopf hereinerstreckt, die ganze vordere Fläche der hinteren Wand des Kehlkopfes ïberzieht und wohl ohne Unterbrechung in den Ueberzug der hinteren Wand der Trachea übergeht, der gleichfalls durch geschichtetes Pflasterepithel gebildet wird ${ }^{2}$ ).

Wir bekommen also ein ausserordentlich buntes Bild (Fig. 2), das in mehrfacher Beziehung von dem von Rheiner gegebenen Schema der Epithelvertheilung (Fig. 1) abweicht.

Hat das bunte Mosaik, welches die Anordnung der Epithelien in jedem einzelnen Kehlkopfe darstellt und das, wie wir sahen, noch weitere Schwankungen aufweist, wenn wir mehrere

1) Luschka, Der Kehlkopf des Menschen. Tübingen 1871. S. 102.

2) Bockendahl, Ueber die Regeneration des Tracbealepithels, Arch. f. mikroskop. Anat. Bd. 24. 1885. 
Kehlköpfe mit einander vergleichen, auf den ersten Blick zweifellos etwas Befremdliches, so verliert es doch das Wunderbare, wenn wir die topographischen Beziehungen des Organes berücksichtigen, besonders aber, wenn wir seine entwickelungsgeschichtlichen Beziehungen zu Rathe ziehen.

Was zunächst die Lage des Kehlkopfes anbelangt, "so sehen wir ihn an der Kreuzungsstelle zweier Kanäle aufgehängt, von denen der eine den Weg fär die dem Körper zuzuführenden festen und flüssigen Nahrungsmittel darstellt, während der andere den Austausch der Gase zwischen dem Körper und der umgebenden Luft vermittelt. Da letzterer vorwiegend Flimmerepithel trägt, während ersterer von Pflasterepithel ausgekleidet erscheint, so dürfte das mannichfaltige Ineinandergreifen der beiden Arten des Epithels an der Durchkreuzungsstelle schon verständlicher sein.

Entwickelungsgeschichtlich wissen wir aber durch die Untersuchungen von Ganghofner ${ }^{1}$ ), dass der Kehlkopf aus zwei ganz getrennt entstehenden Stücken hervorgeht, die erst später miteinander verschmelzen. Die primäre Anlage des Kehlkopfes findet nehmlich in Form zweier länglicher, zapfenförmiger Wülste am oberen Ende der Luftröhre statt. Unabhängig davon entwickeln sich die Epiglottis und der Schildknorpel aus der Zungenanlage in Form querer Wülste. Es stellen sich letztere mithin als Gebilde des 3 . und 4 . Kiemenbogens dar, während die eigentlichen Kehlkopfzapfen genetisch zum Darmsystem gehören. Beide Anlagen sind durch eine tiefe, quere Einsenkung von einander getrennt. Aus den Seitentheilen der Kehldeckelanlage wachsen weiterhin die Plicae ary-epiglotticae hervor, die sich mit der Spitze des Kehlkopfzapfens verbinden und so den späteren Kehlkopfeingang herstellen. Ebenso wachsen im oberen Abschnitt von den Seitentheilen der Anlage des Schildknorpels zwei Wülste gegen die Mittellinie herein, die sich ihrerseits wieder mit zwei in sagittaler Richtung symmetrisch entgegenwachsenden Wülsten des Kehlkopfzapfens vereinigen. Dieses Ineinanderwachsen der beiden Theile, von denen der eine zum Trachealrohr gehört,

1) Ganghofner, Beiträge zur Entwickelungsgeschichte des Kehlkopfes. Prager Zeitschr. f. Heilk. 1880 . H. 3 u. 4 und Derselbe, Beiträge u. s.w. 2. Theil. Prager Zeitschr. f. Heilk. B. 2. H. 25. 
das Flimmerauskleidung besitzt, der andere aber zum Zungengrunde, der Pflasterepithel trägt, dürfte den auffallenden Wechsel in der Vertheilung der Epithelien wohl noch besser erklären.

Der Kehlkopf des Neugebornen bietet nach Henle ${ }^{1}$ ) insofern eine Abweichung in seinem Verhalten von dem des Erwachsenen, als hier das Flimmerepithel schon am Rande der Epiglottis seinen Anfang nimmt und deren ganze untere Fläche bekleidet. Auch Verson (a. a. O.) giebt an, dass die ganze hintere Fläche der Epiglottis beim neugebornen Kind von einem ungeführ $0,08-0,1 \mathrm{~mm}$ dicken Flimmerepithel überzogen ist. Es wären mithin die Verhältnisse hier ganz so, wie an der oberen Fläche des weichen Gaumens und an der hinteren Fläche der Uvula, wo man nach den Angaben von Klein beim Neugebornen Flimmerepithel findet, während diese Stellen beim Erwachsenen geschichtetes, nicht flimmerndes Pflasterepithel tragen ${ }^{2}$ ). Bei Kehlköpfen von Kindern in den ersten Lebensmonaten, welche Rheiner (a. a. 0.) untersuchte, fand or die untere Fläche des Kehldeckels überzogen von einem Epithel, „das im Allgemeinen seinen plasterförmigen Charakter beibehielt, nur mit dem Unterschied, dass das relative Verbältniss in den Dimensionen der Zellen sich gleichartiger gestaltete und so am ehesten die Henle'sche Bezeichnung "Uebergangsepithelium" darauf angewendet werden kann". Leider habe ich trotz meiner Bemühungen in dieser Richtung, nur einen Kehlkopf rom Neugebornen erhalten und an diesem war unglücklicherweise das Epithel vielfach schon so defect, dass er sich nicht zu weitergehenden Detailstudien eignete. Es liess sich aber trotzdem so viel mit aller Sicherheit erkennen, dass in diesem Falle die Schleimhaut an der hinteren Fläche des Kehldeckels in ihrem oberen Drittel und an manchen Stellen wohl auch noch weiter unten ein geschichtetes Plattenepithel trug. Ich folge hierbei der Nomenclatur Henle's, indem ich alle Zellen, bei denen der Durchmesser senkrecht zur Oberfläche der Schleimhaut über-

1) Henle, Handb. d. Eingeweidelehre. 2. Aufl. 1877. S. 274.

2) Klein, Ueber das Epithel der Schleimhaut und die Ausführungsgänge der Drüsen des weichen Gaumens und der Uvula des Menschen. Sitzungsber. d. math.-naturw. Classe d. k. k. Akad. d. Wissensch. zu Wien. Bd. 57. 1868. 
wiegt, als Cylinderzellen bezeichne, während ich alle die Zellen, deren grösster Durchmesser zur Schleimhautoberfläche parallel gelagert ist, zu den Pflasterzellen rechne.

Ausserdem besassen bei unsern Nengebornen nicht nur die Stimmbänder, sondern auch die Taschenbänder an ihrem freien Rande einen schmalen Streifen Plattenepithel. Die Epithelvertheilung stimmte also in diesem Falle mit der beim Erwachsenen gefundenen im Wesentlichen überein, nur liess sich hier, in Folge der theilweisen Zerstörung des Epithels, die früher geschilderte inselförmige Einlagerung von Plattenepithel zwischen den Flimmerzellen viel seltener nachweisen. Wohl aber zeigte das Epithel in seinem sonstigen Verhalten manche Abweichungen von dem des Erwachsenen, Abweichungen, die mit der grössten Zartheit der Gewebe des Neugebornen zusammenhängen.

Dies führt uns dazu, die Beschaffenheit des Epithels an einzelnen Stellen noch genauer zu betrachten. Sehen wir uns zunächst das Epithel, welches die Aussenseite der Kehlkopfwandungen, - Vorderfläche des Kehldeckels, Aussenfläche der ary-epiglottischen Falten - überzieht, etwas genauer an, so finden wir auf einer bindegewebigen Grundlage, die durch das Vorhandensein von zahlreichen grösseren und kleineren Papillen eine unregelmässig wellige Oberfläche erhält, ein geschichtetes Plattenepithel in einer Mächtigkeit von 0,113-0,291 mm. Es sind aber die Zellen keineswegs durch die ganze Schicht hindurch gleich beschaffen, sondern sie erscheinen vielmehr in verschiedener Tiefe derselben ganz verschieden gestaltet. $\mathrm{Zu}$ unterst auf der Schleimhaut sitzt eine Schicht von schmalen und niedrigen, cylindrischen Zellen mit längsovalem Kern, die, wie $V$ erson treffend sagt, pallisadenartig aneinandergereiht erscheinen. Darüber folgt eine 4-6fache Lage rundlicher, oder unregelmässig polyedrischer, mannichfaltig ineinandergreifender, eiweissreicher Zellen. Weiter nach oben flachen sich die Zellen mehr und mehr ab, so dass wir zunächst der freien Oberfläche noch eine 8-14fache Lage ausgesprochen plättchenförmiger Zellen haben, deren oberste Schichten stark verhornt sind, so dass ihre Kerne sich nur noch schwach färben und die Zellen sich leicht in Form feiner Lamellen von der Unterlage ablösen.

Diese Beschaffenheit behält das Epithel auf der Aussenseite 
überall bis zum oberen Rande der Kehlkopfshöhle, im Innern des Kehlkopfes jedoch nur an der Vorderfläche der hinteren Wand, in der Regio interarytaenoidea. An allen übrigen Stellen verschwinden am oberen Rande des Kehlkopfes plötzlich die Papillen, die bisher in das Epithel hineinragten, so dass die untere Grenze des Epithels an der hinteren Fläche des Kehldeckels, von ganz geringen Unebenheiten abgesehen, geradlinig ist, während sje an der Innenflüche der ary-epiglottischen Falten einen nur leicht wellenförmigen Charakter darbietet. Auf dieser Grundlage erhebt sich eine nur 0,031-0,081 mm dicke Epithelschicht. Zunächst auf dem Bindegewebe aufsitzend haben wir hier wieder, ganz wie es oben für die Aussenseite geschildert wurde, eine Schicht von niedrigen, pallisadenartig angeordneten Cylinderzellen; darüber eine 3-5fache Lage von rundlichen, oder polygonalen eiweissreichen Zellen und über diesen 3 bis 5 Lagen mehr oder weniger verhornter platter Zellen.

So beim Erwachsenen. Das geschichtete Plattenepithel des Neugebornen unterscheidet sich insofern, als hier die Epithelschicht absolut und relativ niedriger ist, als beim Erwachsenen. Wir haben hier im Ganzen nur 4-6 Lagen Zellen übereinander. Auch sind die Zellen hier noch nicht so deutlich in 3 Schichten geschieden, wie wir dies beim Erwachsenen fauden, indem einmal die Basalzellen noch nicht so ausgesprochen cylindrisch erscheinen, dann aber auch die oberen Zellenlagen noch eher dem Uebergangsepithel, im Sinne Henle's, zuzurechnen sind und nur die alleroberste Lage, wenigstens stellenweise, aus deutlich plättchenförmigen Zellen besteht, die aber hier auch noch eiweissreich sind und Kerne enthalten, die sich intensiv färben.

Auch am freien Rande der Stimmbänder und, wenn daselbst vorhanden, ebenso am freien Rande der Taschenbänder zeigt das Plattenepithel im Wesentlichen das oben für die Hinterfläche des Kehldeckels und die Innenfläche der ary-epiglottischen Falten beschriebene Verhalten. Abweichend ist nur eine auffallende Verjüngung der Epithelschicht unmittelbar auf dem freien Rande der Bänder. Während nehmlich das Epithel oberhalb und unterhalb des freien Randes eine durchschnittliche Dicke von $0,055 \mathrm{~mm}$ besitzt, wird es gegen den freien Rand zu rasch dünner und behält an demselben an der dünnsten 
Stelle nur noch eine Dicke von 0,023-0,026 mm. Die Verdünnung erfolgt vorwiegend dadurch, dass die mittlere Schicht der rundlichen Zellen dünner wird und schliesslich ganz verschwindet, so dass an der dünnsten Stelle des Epithels unmittelbar über den cylindrischen Basalzellen, die hier auch niedriger erscheinen, eine 3-4fache Lage von platten Zellen aufliegt. Nur in den Buchten zwischen den am Rande des Stimmbandes, besonders im hinteren Abschnitt reichlich vorhandenen Papillen schieben sich eine, oder mebrere Lagen rundlicher Zellen zwischen die Basalzellen und die platten Zellen.

Weiterhin zeigen auch die kleineren Inseln von Plattenepithel, die sich in das Flimmerepithel eingelagert finden, ein etwas abweiehendes Verhalten, während die grösseren Inseln durchaus das zuerst gegebene Bild des Plattenepithels im Kehlkopfe wiederspiegeln. Die kleineren Inseln haben nehmlich in ihren unteren und mittleren Zellenlagen theils cylindrische, theils spindelförmige, theils vielgestaltige Zellen, bei denen allen der Durchmesser senkrecht zur Schleimhautfläche überwiegt. Darüber folgt dann unmittelbar, als oberste Schicht, eine zwei- bis mehrfache Lage von Pflasterzellen.

An den Stellen, wo die Schleimhaut flimmert, zeigt das Epithel, wie sowohl Schnitt- als Zupfpräparate lehren, den Charakter des geschichteten Cylinderepithels, eine Thatsache, die zuerst F. E. Schulze ${ }^{1}$ ) gegenüber den Angaben von Reichert und Henle nachgewiesen hat. Die letztgenannten Forscher lehrten nehmlich, dass das Flimmerepithel der Luftwege ungeschichtet sei und besonders Henle ${ }^{2}$ ) behauptete, dass alle Angaben über eine Schichtung des Flimmerepithels auf Täuschung, durch schräggeführte Schnitte hervorgerufen, beruhe. Die flimmertragenden Zellen sind hoch, schmal, senkrecht zur Schleimhautfläche gestellt und verschmälern sich nach unten zu. Bisweilen beginnt die Verjüngung sofort vom oberen Ende ab. In diesen Fällen findet sich um den längsovalen Kern herum, der in der Regel ungefähr in der Mitte des eigentlichen Zellkörpers liegt, so dass wir an Schnitten, die senkrecht zur Schleimhautober-

1) F. E. Scbulze, Epithel und Drüsenzellen. Arch. f. mikrosk. Anat. 1867. Bd. 3. S. 193.

2) a. a. O. S. 49 . 
fläche geführt sind, zunächst dem freien Rande eine kernfreie Zone sehen, eine mehr oder weniger beträchtliche Vorbauchung der Seitenränder der Zellen. In vielen Fällen behält aber die Zelle bis zu der Stelle, wo sich der Kern befindet, die Breite, die sie an ihrem oberen Ende besitzt und spitzt sich erst unterhalb des Kernes mehr oder weniger rasch zu, um schliesslich in einem, oder mehreren feinen fadenförmigen Fortsätzen zu enden. Der Körper der Zelle ist fein gekörnt. Häufig zeigt sich in dem oberhalb des Kernes gelegenen Theile der Zelle eine feine Längsstreifung. Der obere Rand der Zelle, der die feinen, niedrigen, in ihrer Zahl wechseluden Flimmerhaare trägt, ist öfters etwas dunkler, öfters auch doppelt contourirt. Zwischen den Flimmerzellen finden sich vielfach Becherzellen, die ja nach den Beobachtungen von $\mathrm{Knauff}^{1}$ ) und von Waller und Björkmann ${ }^{2}$ ) nur umgewandelte Flimmerzellen darstellen und nach $\mathrm{Knauff}$ die wichtigsten Schleimsecretoren sind. Der durch die meist beträchtliche Verschmälerung der unteren Enden der Flimmerzellen entstehende freie Raum wird ausgefüllt durch zum Theil spindelförmige, zum Theil auch unregelmässig vieleckige Zellen, deren Ecken, ebenso wie die unteren Enden der Flimmerzellen, in feine, fadenförmige Fortsätze auslaufen, welche sich theilweise dann noch weiter in feinere Fädchen spalten. Zu unterst findet sich endlich noch eine Lage von cylindrischen oder kegelförmigen Zellen, die mit einer etwas verbreiterten, stellenweise leicht gezähnten Basalfläche der Bindegewebsschicht aufsitzen.

F. E. Schulze (a. a. 0.) spricht sich dahin aus, dass alle mit Flimmerhaaren versehenen Cylinderzellen mit ihrem unteren Ende die bindegewebige Grundlage erreichen. Auch Drasch vertritt diese Ansicht, während Waller und Björkmann es zweifelhaft lassen, $o b$ dies Verhalten bei allen Flimmerzellen statthat. Auch mir erscheint dies zweifelhaft, ich möchte im Gegentheil, gestützt auf einige Befunde, die ich sehr bald näher berühren werde, annehmen, dass, wenngleich diese Regel für die

1) Knauff, Das Pigment der Respirationsorgane. Dieses Archiv 1867. Bd. 39. S. 442 .

2) Waller und Björkmann, Studien über den Bau der Trachealschleirnhaut mit besonderer Berücksichtigung des Epithels. Biolog. Untersuchungen vọ Retzius. 1882, Bd. 2, S. $71-97$. 
bei Weitem grössere Mehrzahl der Flimmerzellen volle Gültigkeit hat, es doch auch flimmertragende Cylinderzellen giebt, welche mit ihrem unteren Ende die Bindegewebsschicht der Schleimhaut nicht erreichen. Solche Zellen habe ich an Stellen des Uebergangs vom Plattenepithel zum Flimmerepithel beobachtet.

Den Uebergang des Plattenepithels in's Flimmerepithel schildert Verson folgendermaassen: je näher man auf der hinteren Fläche des Kehldeckels dem Epiglottiswulste kommt, um so höher erscheinen die cylindrischen Basalzellen, während die darüberliegende Zelleuschicht entsprechend dünner wird. Durch ein solches Ueberhandnehmen der unteren Cylinderzellen auf Kosten der oberen rundlichen und abgeplatteten verschwinden endlich letztere ganz und die ersteren bilden sich durch einen Flimmerbesatz zu den Flimmerzellen um. - In der von Verson geschilderten Art findet der Uebergang an der Hinterfläche der Epiglottis statt, wo ja auch die oben in ihrem abweichenden Verhalten beschriebenen kleinen Inseln eigentlich nur unvollkommene Uebergangsstellen des Flimmerepithels darstellen, bei denen das andere Extrem, das geschichtete Pfasterepithel, nicht völlig erreicht wird. In gleicher Weise vollzieht sich der Uebergang an der Innenfläche der Plicae ary-epiglotticae und an'der unteren Fläche der wahren Stimmbänder. Von letzterer Stelle ist Fig. 7 entnommen, die einen Frontalschnitt des früher geschilderten Fältchens unterhalb des freien Randes des Stimmbandes darstellt und sehr deutlich zeigt, wie sich die unteren Zellen mehr und mehr strecken, während die darüber noch ein Stück weit deutlich zu verfolgende Schicht Plattenepithel nach und nach immer dünner wird, um schliesslich ganz dem flimmertragenden Cylinderepithel zu weichen, dessen Flimmerhaare in der Figur freilich nur angedeutet sind.

Neben der oben beschriebenen Art des Ueberganges habe jch aber in allen den Fällen, wo sich am Rande des Taschenbandes ein Streifen Plattenepithel fand, an den Rändern desselben noch eine andere Art des Ueberganges beobachtet. Es strecken sich hier nicht die unteren, sondern vielmehr die oberen Zellen. Die Plattenzellen werden allmählich schmäler, während gleichzeitig der Höhendurchmesser derselben zunimmt. Es kom- 
men dann zunächst Zellen, die ebenso hoch als breit sind; diese gehen weiterhin in zunächst noch niedrige, keilförmige Zellen über. Die Keile werden immer höher und weichen schliesslich den früher beschriebenen hohen cylindrischen Flimmerzellen. Aber auch die relativ noch niedrigen Keilzellen tragen schon eine Wimperschicht. An Zupfpräparaten von dieser Stelle traf ich wiederbolt auf keilförmige Zellen mit deutlichen Flimmerhaaren, die keine Spur eines Fortsatzes am unteren Ende erkennen liessen und deren Höhe im Ganzen nur etwa $0,04 \mathrm{~mm}$ betrug, während die Epithelschicht an der Stelle eine Dicke von $0,087 \mathrm{~mm}$ aufwies. Den etwaigen Einwurf, dass die niedrigen, keilförmigen Flimmerzellen durch Zerreissen entstandene Kunstproducte sein möchten, halte ich deshalb für hinfällig, weil ich diese Gebilde in ziemlich zahlreichen Zupfpräparaten von Stellen, die ausschliesslich Flimmerepithel tragen, niemals gefunden habe, während sie mir in Zupfpräparaten von der angegebenen Uebergangsstelle häufig begegnet sind. Die Streckung der tieferen Zellenlagen erfolgt hier erst viel später, erst da, wo die keilförmigen Zellen in die hohen Cylinderzellen übergehen. (Fig. 8. - Isolirte keilförmige Flimmerzellen zeigt Fig. 9 b.)

Auch diese Art des Uebergangs scheint schon früher beobachtet und beschrieben worden zu sein. C. Fr. Naumann bildet nehmlich in seinem oben citirten Werke Taf.5 Fig. 14 einerseits runde und vielgestaltige flimmerlose, andererseits niedrige, keilformige, flimmernde Zellen ab und dazwischen Zellen, die den Uebergang zwischen beiden Formen vermitteln. Zur Erläuterung fügt er die Worte bei: Epithelii celler på öfvergången frản Pflasterepithelium till Flimmerepithelium tagne strax of van ligg. ventriculorum -, die wohl zu deutsch heissen: Epithelzellen vom Uebergang des Pflasterepithels zum Flimmerepithel genommen oben vom Taschenbande. Fig. 15 derselben Tafel stellt den Uebergang der niedrigeren, keilförmigen Flimmerzellen in die hohen cylindrischen Flimmerzellen dar. Da ich nicht Schwedisch verstehe, kann ich leider nicht sagen, ob auch der. Text des Naumanu'schen Werkes eine Bestätigung meiner Beobachtung enthält.

Ausser am Taschenbande fand ich die zuletzt beschriebene Art des Ueberganges häufig noch dort, wo der Streifen Pflaster- 
epithel am freien Rande des wahren Stimmbandes gegen den Sinus Morgagni hin in das Flimmerepithel äbergeht.

In dem Epithel des Kehlkopfes kommen fernerhin in ziemlicher Anzahl eigenthümliche knospenförmige Gebilde vor, die in ihrer Gestalt und in ihrem feineren Bau ganz mit den Geschmacksknospen der Zunge übereinstimmen. Ihr Vorkommen an der hinteren Fläche der Epiglottis wurde zuerst von Verson ${ }^{1}$ ) beobachtet und dann von Krause, Hönigschmied, Shofield bestätigt. Davis, der das Vorkommen becherförmiger Organe im Kehlkopfe eingehender untersuchte, fand sie beim Menschen auch an der Innenseite der Aryknorpel reichlich vor und vereinzelt an der Aussenseite dieser Knorpel dicht unter der Spitze. Beim Hunde fand er sie ferner an der freien Fläche der Stimmbänder und an den ary-epiglottischen Falten. Auch in den von mir untersuchten Kehlköpfen fanden sich regelmässig solche Gebilde vor, doch nicht bei allen in gleicher Menge. Der Rand des Kehldeckels erwies sich, ebenso, wie ein schmaler Saum an den ary-epiglottischen Falten, ganz regelmässig frei von den becherförmigen Organen. Wenige Millimeter unterhalb des freien Randes treten sie aber auf und finden sich dann sowohl in dem zusammenhängenden Pflasterzellenüberzug, als in den Inseln von Pflasterzellen, besonders reichlich im zweiten Viertel der hinteren Kehldeckelfäche, spärlicher auf der Innenfläche der ary-epiglottischen Falten. Auch auf der Innenseite der Aryknorpel waren sie in allen Fällen ziemlich zahlreich vorhanden. Zuweilen scheinen einzelne solche Becher isolirt mitten im Flimmerepithel zu stehen und es neigen sich dann die benachbarten Flimmerzellen über der Knospe von beiden Seiten gegen einander. Bei genauerem Zusehen findet man aber auch hier ganz regelmässig über der Spitze der Knospe eine schmale und dünne Schicht von platten, flimmerlosen Zellen. Auch dieses zunächst ganz wunderbar erscheinende Vorkommen von Geschmacksknospen im Kehlkopfe erklärt sich, wie schon Ganghofner in der ersten seiner früher angeführten Arbeiten betont hat, durch die entwickelungsgeschichtliche Thatsache, dass ein Theil der Kehlkopfswandungen von der Zungenanlage aus gebildet wird, ziem-

1) Sitzungsber. der math.-naturw. Classe der k. k. Akad. d. Wissensch. 7.u Wien. 1868. Bd. 57. 
lich einfach. Es ist nicht unwahrscheinlich, wenngleich noch nicht erwiesen, dass auch die Geschmacksknospen im Keblkopfe mit Fasern des Nervus glossopharyngeus im Zusammenhange stehen. Durch die zahlreichen Lücken des Kehldeckelknorpels sieht man nehmlich nicht nur Ausführungsgänge von Schleimdrüsen und Blutgefässe, sondern gar nicht so selten auch Nervenfasern verlaufen und es ist mithin die Möglichkeit nicht von der Hand zu weisen, dass auf diesem Wege Fasern des Glossopharyngens auf die hintere Fläche der Epiglottis und überhaupt in das Innere des Kehlkopfes gelangen.

Endlich ist hier noch ein Vorkommniss zu erwähnen. Ich habe bei sämmtlichen von mir untersuchten Kehlköpfen in den verschiedensten Tiefen des Epithels das Vorhandensein von Leukocyten ganz regelmässig beobachtet. Es findet auch hier, wie dies Stöhr ${ }^{1}$ ) für die Schleimhaut des Magens, des Darmes and der Bronchien nachgewiesen hat, normaler Weise eine Durchwanderung lymphoider Zellen durch das Epithel statt. Schon Verson constatirte, dass in den Maschenräumen des Bindegewebes der Kehlkopfschleimhaut zahlreiche rundliche, ein- oder mehrkernige Körperchen sich finden, die besonders an den Seiten der Schleimhautgefässe und unmittelbar unter dem Epithel dichter angeordnet sind, an letzterem Orte oft so dicht, dass die sonst scharfe untere Grenze der Epithelschicht dadurch verwischt wird. Auch in der Umgebung der Drüsen und in der der Ausführungsgänge derselben sind die Rundzellen dichter angehäuft. Ueberall, wo sich nahe dem Epithel eine solche stärkere Anhäufung von lymphoiden Zellen findet, sehen wir auch die Epithelschicht selbst stärker von Wanderzellen durchsetzt. Die Durchwanderung der Leukocyten kann so massenhaft werden, dass dadurch das Epithel streckenweise ganz zu Grunde geht und, wie Stöhr zeigte, auf diese Weise "physiologisch wunde Stellen“ entstehen, auf deren grosse Bedeutung für das Zustandekommen gewisser pathologischer Prozesse der genannte Forscher gleichfalls schon hingewiesen hat.

Die eben beschriebene diffuse Infiltration mit Rundzellen,

5) Stöhr, Ueber die peripheren Lymphdrüsen. Sitzungsber. d. physikal. medicin. Gesellsch. in Würzburg, 19. Mai 1883 und Stöhr, Ueber Mandeln und Balgdrüsen. Dieses Archiv Bd.97. H. 2. 1884. 
der lockere Leukocytenhaufen, ist die eine der drei Formen, in denen nach Stöhr die Infiltration der Schleimhaut mit Leukocyten erfolgt. Die anderen beiden Formen sind einmal die compacte, mehr oder weniger scharf begrenzte Infiltration, der compacte Leukocytenhaufen, vielfach als solitärer Follikel bezeichnet, sodann die compacte Infiltration mit bläschenförmigen Gebilden, der eigentliche Follikel. Während Lymphfollikel in der Keblkopfschleimhant verschiedener Thiere - z. B. bei Schweinen, Schafen, Katzen - nach den übereinstimmenden Befunden mehrerer Forscher ganz regelmässig, bei anderen, wie beim Hunde, doch sehr häufig vorkommen, sind unsere Kenntnisse über das Vorkommen derselben im Kehlkopfe des Menschen noch ziemlich mangelhaft, was um so mehr bedauert werden muss, da es ja bekannt ist, welche Rolle die Lymphfollikel an anderen Stellen des Körpers bei verschiedenen pathologischen Prozessen - z. B. den tuberculösen und typhösen Entzündungen im Darmkanal spielen. Lindemann ${ }^{1}$ ) sah mehrmals seitlich in dem Winkel zwischen den Eingangsfalten und der hinteren Fläche des Kehldeckels und in einem Falle auf der ganzen inneren Oberfläche des Kehlkopfes und der Trachea bis zur Bifurcation zahlreiche conglobirte Drüsen, wie Henle diese Gebilde bezeichnet. Nach Luschka ist die Schleimhaut des menschlichen Kehlkopfes unter normalen Verhältnissen frei von adenoider Substanz; er hat aber doch, in Ausnahmsfällen, ohne dass der Larynx Zeichen irgend welcher pathologischen Alteration darbot", an der hinteren Seite des Kehldeckels und an der Grenze zwischen diesem und der Plica ary-epiglottica solitäre Follikel angetroffen. - Hoyer jst, wie er sich mündlich gegen Heryng ${ }^{2}$ ) geäussert hat, der Meinung, dass die Lymphfollikel stets pathologische Gebilde darstellen.

Unter meinen Kehlköpfen zeigten nur No. 1 und No. 3, die sonst keinerlei Zeichen einer pathologischen Veränderung der Schleimhaut darboten, solitäre Follikel und zwar nicht nur an den von Luschka und von Lindemann beschriebenen Stellen,

1) Lindewann, Ueber die Nerven der Keblkopfschleimbaut. Zeitschr. f. rat. Medicin. 3. Rate. Bd. 36. 1869. S. $148 \mathrm{ff}$.

2) Heryng, Die Heilbarkeit der Kehlkopfschwindsucht und deren chirurgische Behandlung. Stuttgart 1887. S. 11.

Archiv f. pathol. Anat. Bd. 118. Fift. 2 . 


\section{8}

sondern bei No. 1 auch im Sinus Morgagni, wo sie theils an der äusseren Wand sassen (Fig. 10), theils im Scheitel des Ventrikels, da, wo die äussere Wand in die innere übergeht. Die Follikel zeigten eine ungefähre Länge von $0,5-1 \mathrm{~mm}$ und eine Breite von $0,3-0,5 \mathrm{~mm}$. Ueber ihnen war das Epithel entschieden reichlicher von Rundzelien durchsetzt, als an anderen Stellen. Lockere Leukocytenhaufen fanden sich auch bei den übrigen Kehlköpfen ziemlich constant auf der Höhe der ary-epiglottischen Falte.

Die so sehr verschiedenen diesbezüglichen Befunde und die in Folge dessen auch sehr verschiedenen Anschauungen von diesen Gebilden dürften sich wohl durch die auch für andere Schleimhautabschnitte festgestellte hochgradige Veränderlichkeit der lymphoiden Gebilde erklären. Wenn ich die angeführten Thatsachen mit den Verbältnissen an anderen Schleimhautstellen vergleiche, so möchte ich mich der Ansicht zuneigen, dass auch in der Kehlkopfschleimhaut die Infiltrationen von lymphoiden Zellen in den angeführten verschiedenen Formen noch in das Bereich des Normalen fallen.

Ausser diesen sogenannten conglobirten Drïsen giebt es im Kehlkopfe bekanntermaassen acinöse Drüsen in grosser Menge, zum Theil ordnungslos zerstreut, zum Theil in grösseren Haufen. Die Haufen beschreibt Luschka als Glandulae aggregatae anteriores laryngis, die unter der Membrana hyo-epiglottica liegen und ihre Ausführungsgänge durch die Lücke des Kehldeckelknorpels auf die hintere Fläche der Epiglottis schicken (Fig. 3) - ferner als Glandulae aggregatae posteriores s. interarytaenoideae im ganzen Umkreis der Incisura interarytaenoidea, die Acini liegen theils vor, theils hinter und zum Theil auch zwischen den Fasern des Musculus arytaenoideus transversus; die Ausführungsgänge der hinter dem Muskel gelegenen Drüsen gelangen durch den Muskel hindurch an die Oberfläche der Kehlkopfshöhle; - endlich die Glandulae aggregatae laterales in den Taschenbändern und den ary-epiglottischen Falten. Die an der hinteren Fläche des Kehldeckels befindlichen Drüsen liegen in mehr oder weniger tiefen Nieschen des Knorpels. Diese Nieschen und Lücken des Kehldeckelknorpels sind es auch, wie hier nebenbei bemerkt werden möge, welche bei ulcerösen Zerstörungen des 
oberen freien Kehldeckelabschnittes die sägeförmige Beschaffenheit des Randes bedingen.

Nach Luschka fehlen den wahren Stimmbändern die Drüsen gänzlich. Im Gegensatz dazu habe ich bei einigen meiner Kehlköpfe (bei No. 4 und bei einem der Kehlköpfe, die wegen vorgeschrittener Maceration für die Untersuchung des Epithels ungeeignet waren) ganz wie es Heryng als ziemlich stabil vorkommend beschreibt und abbildet ${ }^{1}$ ), im hinteren Abschnitte des Stimmbandes, ungefähr der Spitze des Processus vocalis entsprechend, zwei kleine Drüschen gefunden.

Die acinösen Drüsen des Kehlkopfes scheinen sämmtlich Schleimdrüsen zu sein, wenigstens habe ich bei dahingehender Prüfung meiner Präparate nie den serösen Drüsen Heidenhain's und v. Ebner's entsprechende Bilder gefunden.

Die Ausführungsgänge der Drüsen, die ein cylindrisches, stellenweise - und zwar besonders an der dem Sinus Morgagni zugekehrten Fläche des Taschenbandes - flimmerudes Epithel tragen, verlaufen theils ziemlich senkrecht und gestreckt gegen die Oberfläche, theils mehr schräg und geschlängelt. Ziemlich häufig findet sich unmittelbar unter der trichterförmigen Mündung an der Oberfläche der Schleimhaut eine ampullenförmige Erweiterung des Ausführungsganges, an welcher der Durchmesser des Ganges das 3-4fache von dem an der Mündungsstelle betragen kann, ein Verbalten, das sowohl senkrechte Schnitte (Fig. 11), als auch Serien von Flächenschnitten deutlich zeigen. Bei einem von mir gemessenen Ausführungsgange betrug die Lichtung an der Mündungsstelle $0,029 \mathrm{~mm}$, dagegen nur $0,258 \mathrm{~mm}$ von der Mündung entfernt $0,120 \mathrm{~mm}$ und verengerte sich bis zu einer Entfernung von $0,581 \mathrm{~mm}$ von der Oberfläche wieder bis auf $0,03 \mathrm{~mm}$. Auch wenn, was öfter geschieht, mehrere Ausführungsgänge sich zu einem vereinigen, finden sich an der Vereinigungsstelle nicht selten ampullenartige Hohlräume. Es wäre wohl möglich, dass diese normaler Weise vorhandenen ampullenförmigen Erweiterungen das Entstehen mancher pathologischen Prozesse begünstigten.

Für die Schleimdrüsen der Trachea hat Orth $^{2}$ ) solche

1) a. a. O. S. 12 und Tafel 2 Fig. 2.

2) Orth, Cursus der Histologie. 1878. S. 209. 
spindelförmige Erweiterungen des Ausführungsgänge als etwas Normales beschrieben und abgebildet. In der Kehlkopfschleimhaut wurden "wurstförmige Erweiterungen" der Ausführungsgänge meines Wissens bisher nur als eine Folge pathologischer Veränderungen beobachtet ${ }^{1}$ ). Erst neuerdings hat $\mathrm{Hoyer}^{2}$ ) gefunden, dass beim Menschen die Ausführungsgänge in der Pars arytaenoidea, an den Processus vocales und an der vorderen Fläche der hinteren Larynxwand kurz vor ihrem Austritt recht anseholiche Erweiterungen besitzen.

Fassen wir nun zum Schluss die hauptsächlichsten Ergebnisse der vorstehenden Untersuchungen nochmals kurz zusammen:

Am oberen Rande der Keblkopfshöhle haben wir ringsherum einen Saum von Pflasterzellen, der mit dem Pflasterepithel der Mund- und der Schlundhöhle unmittelbar zusammenhängt. Plattenepithel überzieht ferner die ganze Regio interarytaenoidea. Im Zusammenhang mit letzterem Ueberzug findet sich ausserdem ein schmaler Streifen von Pflasterzellen regelmässig am freien Rande der wahren Stimmbänder, öfters auch am freien Rande der Taschenbänder. - Auf der hinteren Fläche des Kehldeckels und auf der Membrana quadrangularis schliesst sich an den oberen Saum von Plattenepithel ein Bezirk, in dem das flimmernde Cylinderepithel von zahlreichen Inseln von Plattenepithel unterbrochen ist. An allen übrigen Stellen findet sich Flimmerepithel, das nur vereinzelte kleine Inseln von Plattenzellen einschliesst.

Der Uebergang vom Plattenepithel zum Flimmerepithel erfolgt einmal durch Streckung der unteren Zellen mit allmählichem Schwinden der oberen Sehicht platter Zellen, sodann aber zweitens durch vorwiegende Streckung der oberen Zellen.

Durchwanderung von Lymphzellen durch das Epithel findet im Kehlkopfe genau so wie an anderen Schleimhäuten statt.

Sogenannte solitäre Follikel können im Kehlkopfe unter normalen Verhältnissen vorkommen, finden sich aber im Ganzen selten. Dagegen ist eine mehr diffuse lymphoide Infiltration der Schleimhaut constant nachzuweisen.

Die sehr zahlreichen acinösen Drüsen scheinen sämmtlich

1) Heinze, Die Kehlkopfsschwindsucht. 1879. S.66.

2) Heryng, a. a. O. S. 19. 
Schleimdrüsen zu sein. Ihre Ausführungsgänge zeigen häufig nahe der Mündung eine ampullenförmige Erweiterung.

Auch am Rande der wahren Stimmbänder finden sich über der Spitze des Processus vocalis mitunter einige acinöse Drüsen.

Im Anschluss an vorstehende Untersuchungen über die Beschaffenheit des Epithels und der Drüsen des normalen menschlichen Kehlkopfes habe ich während meiner 4monatlichen Assistentenzeit am pathologisch-anatomischen Institut in Erlangen untersucht, wie sich diese Dinge an einigen Kehlköpfen verhielten, deren Epithel sich schon makroskopisch verändert zeigte. Es standen mir im Ganzen 4 Kehlköpfe zur Verfügung, an denen das Epithel in mehr oder weniger grosser Ausdehnung deutlich verdickt war. Von diesen Kehlköpfen stammten 3 von tuberculösen Individuen und zeigten selbst charakteristische tuberculöse Veränderungen, theils in Form der tuberculösen Infiltration, theils in Form von mehr oder weniger ausgedehnten Ulcerationen. Die Individuen, von denen diese Kehlköpfe genommen sind, waren ein 21jähriger Flaschner (1888, Sect.-Prot. 247), ein 23jähriger Schreiner (1888, Sect.-Prot. 248) und ein 39jähriger Tagelöhner (1888, Sect.-Prot. 260). Bei allen fand sich sonst eine chronische Tuberculose der Lungen mit Cavernenbildung, pleuritische Adhäsionen, tuberculöse Geschwüre in der Trachea und in Dünn- und Dickdarm.

Was das makroskopische Verhalten der Kehlköpfe betrifft, so will ich hier nur den des 23jährigen Schreiners genauer schildern, da die anderen beiden in Bezug auf die hier vorzugsweise interessirenden Verhältnisse genau dasselbe Bild aufwiesen und nur hinsichtlich der Zahl und Ausdehnung der Geschwüre geringe Abweichungen darboten. - Die Epiglottis zeigt eine ziemlich normale Form, ihr oberer Rand ist noch scharf, aber die seitlicheu Ränder sind etwas rundlich verdickt, ebenso wie die sich nach hinten anschliessenden Plicae ary-epiglotticae. Durch die Infiltration der Schleimhaut ist die Form der Wrisberg'schen Knorpel, sowie die der Santorini'schen und Giessbeckenknorpel verwischt. Die seitlichen Wände der oberen Kehlkopfhöhle sind nicht, wie dies normaler Weise geschieht, durch eine ziemlich scharfe Grenze von den Taschenbändern geschieden, sondern 
gehen ganz allmählich in dieselben über. Die Taschenbänder selbst sind gleichfalls etwas verdickt, wodurch der Eingang zum Sinus Morgagni etwas verengert erscheint. Auch die Stimmbänder haben ihre zierliche prismatische Gestalt gegen eine mehr dicke, rundliche vertauscht. Die Schleimhaut fühlt sich im Ganzen auffallend derb an and zeigt eine gelblichgraue Färbung. Von diesem Grunde heben sich einige Stellen durch milchweisse Färbung ziemlich deutlich ab. Es sind dies vor Allem die freien Ränder der Stimmbänder und die unteren Flächen derselben in mehr oder weniger bedeutender Ausdehnung, in geringerem Grade auch die freien Ränder der Taschenbänder; von da erstreckt sich die milchweisse Färbung über die inneren Flächen der Aryknorpel und durch die Regio interarytaenoidea nach dem Kehlkopfrand hinauf and macht sich an dem oberen Rande der Kehlkopfwandungen selbst noch an einzelnen Stellen, besonders in den hinteren Abschnitten, bemerklich. Die milchweissen Stellen ragen ein wenig über das Niveau der umgebenden Schleimhaut hervor and machen vielfach durch Abschilferung einen etwas rauhen Eindruck. Streicht man über die weissen Stellen hinweg, so lassen sich leicht kleine Schuppen abstreifen, die, wie die mikroskopische Untersuchung lehrt, aus Plattenepithel bestehen. Inmitten der weissen Stellen fanden sich auf dem hintersten Abschnitt der Stimmbänder und sich von da über den Processus vocalis bis auf die Innenfläche des betreffenden Aryknorpels erstreckend, Geschwüre von wenigen Millimetern Breite und ungefähr doppelter Länge, mit unregelmässigem, zackigem Rande. Auf dem leicht höckerigen Grunde der Geschwüre war der Aryknorpel mit der Sonde deutlich zu fühlen. In dem einen Falle (Sect.-Prot. 248) sass über dem linken Processus vocalis ein ringförmiges Geschwür, das eine Insel von erhaltenem Epithel umschloss. Tuberculöse Geschwüre von der bekannten Beschaffenheit sassen an der Vorderfläche der hinteren Larynxwand. In einem Falle befanden sich auch über den unteren Abschnitten des Kehldeckels mehrere Geschwüre.

Die mikroskopische Untersuchung dieser Kehlköpfe zeigte nun, dass die Anordnung und Vertheilung des Epithels hier bei allen in gleicher Weise eine durchaus andere ist, als wir sie bei den normalen Kehlköpfen kennen gelernt haben. Flimmerepithel 
findet sich hier nur noch in den oberen Abschnitten der Sinus Morgagni und auch da nur auf verhältnissmässig kleinen Strecken gut erhalten. Dazwischen befinden sich Partien, wo das Epithel aufgefasert und von zahlreichen Rundzellen durchsetzt erscheint und dies mitunter auch an Stellen, wo kein Tuberkelknötchen unter dem Epithel liegt. An anderen Abschnitten ist die oberste, Flimmerhaare tragende Zellenschicht gänzlich abgestossen, so dass die Epitheldecke hier ausser aus der untersten Schicht der pallisadenartig angeordneten Zellen nur noch aus 1-2 Lagen vorwiegend länglicher, vielgestaltiger Zellen besteht. Die abgestossenen Flimmerzellen sieht man vereinzelt noch neben anderen Epithelzellen und massenhaften Rundzellen in dem Secret liegen, das den Sinus Morgagni erfüllt.

Vom Rande des Taschenbandes nach oben bis zur oberen Grenze der Kehlkopfhöhle findet sich aber, ebenso wie unterhalb des freien Randes des Stimmbandes, nur geschichtetes Plattenepithel und Epithel von der Art, die wir früher mit Henle als Uebergangsepithel bezeichneten. Das Epithel ist an diesen Stellen gegen die Norm wenig oder gar nicht verdickt und grenzt sich gegen die Bindegewebsschicht der Schleimhaut durch eine im Ganzen gerade Linie ab.

Anders aber an den Stellen, die schon makroskopisch etwas verdickt und weiss verfärbt erschienen. Hier sieht man, ganz besonders stark am freien Rande des Stimmbandes und eine Strecke weit unterhalb desselben, sowie an der inneren Fläche des Aryknorpels und der Vorderfläche der hinteren Larynxwand, geringer an der oberen Fläche des Stimmbandes und viel geringer am Rande des Taschenbandes eine ganz gewaltige Dickenzunahme der Epithelschicht: bis über 50 Lagen Zellen übereinander vermochte ich zu zählen. Die Zunahme erstreckt sich auf alle Schichten, besonders aber auf die obersten Lagen der platten Zellen und die mittleren Schichten der rundlichen und polygonalen Zellen. Vielfach konnte man hier auch wahrnehmen, wie sich das Plattenepithel an der Oberfläche schichtenweise abstösst. An diesen Stellen ist nun auch die untere gerade Grenzlinie des Epithels völlig verschwunden. Das Epithel zeigt sich vielmehr tief ausgebuchtet; auf den Schnittpräparaten erscheinen Epithelzapfen von verschiedener Mächtigkeit von einander durch 
theils schmälere, theils breitere Papillen getrennt, die tief in das Epithel hineinragen, ohne jedoch an der Oberfläche des Epithels eine erheblichere Unebenheit zu erzeugen. Nur über dem Processus vocalis sah ich an dem einen Kehlkopf, wie auch der Epithelüberzug die Zottenform des Bindegewebes nachahmte. Die einzelnen Hervorragungen waren aber so dicht gestellt und die freien Spalträume, welche dieselben trennten, so schmal, dass sie makroskopisch nicht wahrgenommen werden konnten.

Neben dem Epithel zeigt sich auch die bindegewebige Schicht der Schleimhaut bedeutend verdickt und diffus von Rundzellen in viel stärkerem Grade infiltrirt, als dies normaler Weise der Fall ist. In dem diffus infiltrirten Gewebe fallen an einzelnen Stellen reichlichere, an anderen spärlichere Tuberkelknötchen in verschiedenen Entwickelungsstadien, zum Theil mit deutlichen Riesenzellen, in die Angen. Die Blutgefässe der Schleimhaut erscheinen nicht unerheblich erweitert. In ihrer Umgebung findet sich eine stärkere Anhäufung von Rundzellen. Auch an den Schleimdrüsen sieht man das interacinöse Gewebe stark von Rundzellen durchsetzt, an einigen Stellen so stark, dass die normale Form und Structur der Acini dadurch ganz verschwindet. Die Ausführungsgänge der Drüsen sind dabei zum Theil noch ganz unverändert, wenn man von der stärkeren Zellenanhäufung in ihrer Umgebung absieht; zum Theil aber sind sie auf's Vierfache und darüber erweitert, wobei aber das Cylinderepithel derselben noch gut erhalten ist.

Der vierte von mir untersuchte Kehlkopf stammte von einem 48jährigen Gastwirth (Privatsection), bei dem sich in der Spitze der einen Lunge ein verkäster tuberculöser Knoten und einige frische Tuberkel gefunden hatten, sonst aber nirgends eine Spur von Tuberculose, ausserdem beginnende Cirrhose der Leber und acute parenchymatöse Nierenentzündung. Im Kehlkopf, den ich erst in Alkohol liegend zu Gesicht bekam, so dass die feineren Farbenunterschiede verwischt waren, zeigten die einzelnen Theile, soweit sich dies nach der Alkoholeinwirkung noch beurtheilen liess, im Ganzen die normale Configuration, nur erschienen die Stimmbänder etwas verdickt. In den hinteren Abschnitten derselben machte sich entlang dem freien Rande und an der unteren Fläche, schwächer auch an der oberen, eine Verdickung des 
Epithels bemerklich. Dasselbe erschien an den genannten Stellen weisser und rauher, als sonst im Kehlkopfe. Am stärksten trat diese Veränderung über den Processus vocales hervor. Hier zeigte sich beiderseits eine $6 \mathrm{~mm}$ lange und $3 \mathrm{~mm}$ breite, flache, ovale Grube, deren längster Durchmesser schräg von hinten oben nach vorn unten gerichtet war und die von einem höheren Epithelwalle umgeben war. Auch über den Falten der Regio interarytaenoidea war das Epithel weisser und rauher, als im übrigen Kehlkopfraume. Es war also makroskopisch ganz das Bild vorhanden, wie es Virchow in seinem Vortrage über Pachydermia laryngis ${ }^{1}$ ) als ein bei alten Säufern häufig vorkommendes geschildert hat. - Was den mikroskopischen Befund anlangt, so fand sich hier, vollkommen wie an den verdickten weissen Epithelstellen der oben beschriebenen tuberculösen Kehlköpfe, das Epithel hochgradig verdickt. Auch hier erscheint das Epithel an seiner unteren Fläche durch gefässhaltige Bindegewebspapillen, die in dasselbe hineinragen, in zahlreiche Zapfen zerlegt. Auch hier sehen wir in der verdickten Bindegewebsschicht abnorm reichliche und ungewöhnlich weite Gefässlumina und eine diffuse reichliche zellige Infiltration, die in der subepithelialen Zone und in der Umgebung der Gefässe, sowie in der Umgebung der gleichfalls erweiterten Ausführungsgänge der Drüsen höhere Grade angenommen hat. Auch das interacinöse Gewebe der Drüsen enthält reichliche Rundzellen. Abweichend von dem Verhalten der früher geschilderten Kehlköpfe ist aber hier das Fehlen der Tuberkelknötchen, abweichend ist ferner besonders die normale Beschaffenheit des Epithels an allen Stellen, die nicht schon makroskopisch durch ihre weisse Verfärbung auffielen.

Wir sehen also bei allen 4 untersuchten Kehlköpfen übereinstimmend, dass die Schleimhaut an den Stellen, die, wie wir bei unseren früheren Untersuchungen fanden, regelmässig von Plattenepithel bedeckt sind und die ausserdem die Eigenthümlichkeit besitzen, dass sie bei den functionellen Bewegungen des Kehlkopfes am meisten mechanischen Reizen ausgesetzt sind, einen mehr dermoiden Charakter angenommen hat, indem sich einmal die Schichten des Epithels bedeutend vermehrt haben,

1) Berlin. klin. Wochenschr. 1887, No. 32. S. 585 ff. 
sodann aber auch die vorher kaum angedeuteten Papillen eine beträchtliche Grösse und Menge erlangt haben.

Fragen wir nach der Genese dieser Veränderungen, so scheint die gleichzeitige Dickenzunahme der Bindegewebsschicht der Schleimhaut, das weite Lumen der Ausführungsgänge, die auffällige Weite der zahlreichen Gefässe und die reichliche zellige Infiltration der Schleimhaut darauf hinzudeuten, dass es sich hier um eine Hypertrophie der gesammten Schleimhaut auf chronisch entzündlichem Boden handelt. Chronische Katarrhe der Schleimhaut des Kehlkopfes sehen wir ja bei Tuberculose der Lungen neben Katarrhen der Schleimhaut der Trachea und der Bronchien sehr gewöhnlich, ebenso wie bei den Rachenkatarrhen der Potatoren ein Uebergreifen auf den Kehlkopf eine häufige Erscheinung ist. Allerdings erstrecken sich die Potatorenkatarrhe oft über die ganze Kehlkopfschleimhaut; oft sieht man aber auch, wie in unserem Falle, nur den hinteren Abschnitt und die Stimmbänder davon befallen. Dass in allen unseren Fällen vorwiegend, oder ausschliesslich die Veränderungen in den hinteren Abschnitten sitzen, dürfte seinen Grund wohl in dem Umstande haben, auf den zuerst Schottelius ${ }^{1}$ ) aufmerksam gemacht hat, dass nehmlich durch heftige und häufige Contractionen. des Musc. arytaenoideus transversus, wie sie häufige Hustenstösse, oder vielfaches lautes Singen und Schreien mit sich bringen, eine abnorme Blutzufuhr zu den über dem Muskel liegenden Schleimhautabschnitten bedingt wird, die ihrerseits dann die Hypertrophie der Schleimbaut in allen ihren Schichten zur Folge hat.

Auffallend ist aber, dass dabei nicht eine einfache Dickenzunahme der einzelnen Schichten erfolgt, sondern dass sich die Grenze zwischen Epithel und Bindegewebsschicht durch das Auftreten von Papillen in eigenthümlicher Weise verändert. Auspitz ${ }^{2}$ ) lebrt, dass die papilläre Begrenzung dadurch entsteht, "dass die Epidermis zapfenartige Fortsätze in die ihr in toto entgegen-

1) Schottelius, Zur Aetiologie einfacher Kehlkopfgeschwüre. Kassel 1880 ausfübrlich referirt bei Heryng, Die Heilbarkeit der Larynxphthise. 1888. S. 23 A.

2) Auspitz, Ueber das Verhältniss der Oberbaut zur Papillarsehicht, insbesondere bei pathologischen Zuständen der Haut. Arch. f. Dermat. u. Syph. II. 1870. S. $24 \mathrm{ff}$. 
wachsende Lederhaut vorschiebt". Je dicker die Epidermis an einer Stelle ist, desto länger sind daselbst die Papillen. Ein gleichos Verhalten nimmt er für die Schleimhäute an. Nach seinen Ausführungen ist es mir aber nicht verständlich, wodurch an den verschiedenen Stellen des so gleichmässig gestalteten Epithels eine so verschiedene Wachsthumsenergie bedingt sein soll. Auch scheint mir die Auffassung, dass sich Epithelzapfen in das Bindegewebe hineinerstrecken, keineswegs richtig und nur durch unsere senkrecht zur Schleimhautoberfläche geführten mikroskopischen Schnittpräparate erweckt zu sein, die allerdings ein solches Verhalten vortäuschen. In Wirklichkeit erstrecken sich:aber bei der Cutis nicht Epithelzapfen in das Bindegewebe, sondern wie dies Flachschnitte deutlich lehren, umgekehrt gefässführende Zapfen von Bindegewebe, d. h. Papillen, in die zusammenhängende Epithelschicht und in gleicher Weise liegen die Verhältnisse auch bei unseren pachydermischen Schleimhautstellen. Ich möchte daher vielmehr annehmen, dass die Veränderung sich folgendermaassen entwickelt. In Folge der vermehrten Blutzufuhr werden zunächst sowohl die Bindegewebsschicht als die Epithelschicht gleichmässig zunehmen. Die Bindegewebsschicht setzt sich aber aus den verschiedensten Elementen zusammen. Hier erklärt sich also eine ungleichmässige Zunahme viel leichter. Es sind offenbar die Gefässe, die sich nicht nur erweitern; sondern sich auch zusammen mit ihrer nächsten Umgebung strecken und wohl auch durch Sprossenbildung neue Aeste aussenden und so ein solches ungleichmässiges Wachsthum bedingen. Nicht gar selten sieht man Gefässe, die der unteren Grenze des Epithels eben anliegen und nur eine leichte Einbuchtung daselbst hervorrufen, daneben sind andere Gefässe zu sehen, die schon tiefer in die Epithelschicht hineinragen, während die untere Grenzlinie des Epithels beiderseits von denselben geradlinig weiterverläuft.

Schliesslich will ich noch erwähnen, dass bei all' den untersuchten pathologischen Kehlköpfen, wie dies auch Hünermann ${ }^{1}$ ) anführt, die Knorpel, selbst bei den jugendlichen Individuen,

1) Hünermann, Ueber Pachydermio und Geschwürsbildung auf den Stimmbändern. Inaug.-Diss. Berlin 1881. 
auffallend stark verknöchert waren, was wohl auch als eine Folge der chronischen Entzündung aufzufassen ist.

\section{Erklärung der Abbildungen. \\ Tafel X-XI.}

Fig. 1. Schema der Epithelvertheilung im Kehlkopfe nach Rbeiner.

Fig. 2. Schema der Epithelvertbeilung im Keblkopfe nach vorstehenden Untersuchungen.

In beiden Figuren bezeichnet:

a untere Fläche des Kebldeckels. b Schildknorpel. c Ringknorpel. d Giessbeckenknorpel und Santorini'sches Hörnchen. e Plica aryepiglottica. f Ligamentum thyreo-arytaenoideum superius. g Ligamentum thyreo-arytaenoideum inferius. b Sinus Morgagni. \& Membrana quadrangularis. Iflil bei $g$ und $i$ constant Plattenepithel. mil bei $\mathrm{f}$ mitunter Plattenepithel. (I) bei $\mathrm{a}$ und $\mathrm{k}$ Inseln von Plattenepithel.

Fig. 3. Sagittalschnitt durch die Epiglottis von Keblkopf No. 1 nahe der Mittellinie. 5fache Vergrösserung. B Blutgefässe. D Drüsen. K Knorpel. A Ausführungsgang.

…. Plattenepithel. 펭 Flimmerepithel. …. Uebergangsepithel.

NB. Diese Zeichen baben in Fig. 4,5 und 6 dieselbe Bedeutung.

Fig. 4. FrontaIschnitt durch das hintere Drittel der ary-epiglottischen Falte von Keblkopf No. 1. 5fache Vergrösserung. D Drüsen. GK Geschmacksknospen. L Leukocytenhaufen. M.a.e. M. ary-epiglott. S.t.m. Stratum thyreo-membranosum. C.W. Cartilago Wrisbergii.

Fig. 5. Frontalschnitt durch das rechte Taschenband von Kehllopf No. 1. 5fache Vergrösserung.

Fig. 6. Frontalschnitt durch das rechte Stimmband von Kehlkopf No. 1. 5fache Vergrösserung. f das im Text geschilderte Fältehen unter dem freien Rande. D Drüsen. M.th. a. Musc. thyreo-aryt. intern.

Fig. 7. Uebergang des Plattenepithels in das Flimmerepithel durch Streckung der Basalzellen, vom unteren Rande des Stimmbandes. Frontalschnitt durch das erwähnte Fältchen. Leitz, Ocular 1, Objectiv 7.

Fig. 8. Uebergang des Plattenepithels in das Flimmerepithel durch Streckung der oberen Zelten, von der oberen Fläche des Taschenbandes. Leitz, Ocular 1, Objectiv 7. Die dunklen Punkte im Epithel markiren durchwandernde Lymphzellen.

Fig. 9. Isolirte Zellen von der Uebergangsstelle am Rande des Taschenbandes. Leitz, Ocular 1, Objectiv 7 .

Fig. 10. Solitärer Follikel im Sinus Morgagni. Keblkopf No. 1. 5fache Vergrösserung. F Follikel.

Fig.11. Zwei ampullenförmig erweiterte Ausführungsgänge von der oberen Fläche des Taschenbandes. Keblkopf No. 5. 5fache Vergrösserung. A Ausführungsgang. D Drüsen. 